\title{
A Cross-Sectional Survey on Telemedicine Use for Doctor-Patient Communication
} Aelia Akbar ${ }^{1}$, Aqsa Iqbal ${ }^{2}$, Dominic Gaziano ${ }^{3}$, Filip Gasior ${ }^{4}$, Ayesha J. Zaidi ${ }^{4}$, Anum Iqbal ${ }^{5}$, Abigail Silva

1. Public Health, Loyola University Medical Center, Chicago, USA 2. Internal Medicine, Northeast Georgia Medical Center, Gainesville, USA 3. Internal Medicine, Amita Health, Chicago, USA 4. Internal Medicine, University of Illinois at Chicago, Chicago, USA 5. Internal Medicine, Liaquat University of Medical and Health Sciences, Hyderabad, PAK

Corresponding author: Aelia Akbar, aeliausmle@gmail.com

\section{Abstract \\ Introduction}

Use of computers for doctor-patient communication is increasing. Considering effective doctor-patient communication is important for good health outcomes. This study helps to determine the level of acceptance of telemedicine in general public and factors associated with it.

\section{Methods:}

This survey with cross-sectional analysis comprised a brief survey with 15 questions. The survey was distributed in public places to determine the opinions of the general public.

\section{Results}

Randomly selected 125 participants completed the questionnaire. Synchronous telemedicine was favored by young people ( $82 \%$ in the 18 -34 age group vs $37.5 \%$ of participants aged $>55$ years; $p<0.01$ ), those with a higher education level (46.7\% of non-college-educated persons vs $80.6 \%$ of college-educated persons; $\mathrm{p}<0.01$ ), and frequent computer users (67\% who used a computer for less than two hours a month vs $86.5 \%$ of those who used a computer more than hours a month; $\mathrm{p}=0.03$ ). Asynchronous communication, like sending health information to doctors via a safe portal was acknowledged mostly by people who had used patient portals in the past ( $84.1 \%$ vs $65.4 \%$; $=0.02$ ). Use of patient portals was less among older users and senior citizens $(20.8 \%$ use in the age group $>55$ vs. $51.3 \%$ in the age group $35-53$ years vs. $71 \%$ in age group 18-34 years). Receiving video education for specific health concerns was favored by those who used a computer frequently $(94.6 \%$ who used a computer more than two hours a month vs $77 \%$ who used a computer less than two hours a month; $\mathrm{p}=0.02$ ).

\section{Conclusion}

Received 08/23/2020 Review began $08 / 25 / 2020$ Review ended 08/31/2020 Published 09/12/2020

\section{๑) Copyright 2020}

Akbar et al. This is an open access article distributed under the terms of the Creative Commons Attribution License CC-BY 4.0., which permits unrestricted use, distribution, and reproduction in any medium, provided the original author and source are credited.
Telemedicine is generally favored, but physicians should be mindful about older people as they may not feel comfortable. Step by step guidance should be provided especially to senior citizens for telemedicine and portal use.

Categories: Family/General Practice, Internal Medicine, Healthcare Technology

Keywords: telemedicine, patient-doctor communication, telehealth, patient portal, patient-doctor relation

\section{Introduction}

Effective doctor-patient communication is important for history gathering, building trust, and patient compliance. Studies have shown that effective communication between patient and physician is associated with positive health outcomes [1-4]. Telemedicine is the exchange of medical information through electronic devices between patients and physicians [5,6]. Telemedicine may be used for asynchronous or synchronous doctor-patient communication [7]. In asynchronous communication, the doctor and patient are not connected at the same time. For example, communication through emails, safe patient portals, interpretation of diagnostic tests and pre-visit completion of surveys by patients. Synchronous communication refers to communication when the doctor and patient are connected at the same time, and is usually in the form of video conferencing [7].

Telemedicine increases access to care, saves travel time. and helps bring down costs. During the pandemic of COVID-19, telemedicine became an effective way to prevent the spread of infection without disrupting patients' access to health care. Studies have shown increased access to healthcare and positive health outcomes when telemedicine was used for the management of chronic illnesses, like asthma in schools, and diabetes in rural areas $[8,9]$. 
The purpose of this study was to explore people's perspectives regarding the use of telemedicine for patient access to healthcare.

\section{Materials And Methods \\ Study design and population}

Our survey study took place from 2017 to 2019 in general public places like parks, bus stops, and convenience stores in the city of Chicago, Illinois. People aged 18 years and older were eligible to participate. A written questionnaire was distributed among the people by anonymous study investigators and provided verbal consent to participate. Respondents to the survey remained anonymous and therefore the study was exempt from IRB approval. The individuals who completed the questionnaire did not receive any financial compensation.

\section{Questionnaire}

A research questionnaire consisting of 14 questions was developed by the study investigators. We examined the general acceptance of doctor-patient online communication. We examined two scopes of doctor-patient interaction according to participants' characteristics, (1) acceptance of synchronous telemedicine with doctor communicating directly via computer; and (2) acceptance to asynchronous telemedicine, i.e., receiving health information from doctors on cellphone or computer, receiving appointment reminders on a cellphone, sending health information to the doctor through a safe portal, some health questions being answered before visiting the doctor, receiving wellness reminders through a computer, receiving video education from a doctor, and the doctor seeing and evaluating their patient's health information on an electronic health application.

\section{Data collection and analysis}

A brief verbal review of the study was provided to the people at public places by the study investigators. Participants were randomly selected. Those who verbally consented to participate were asked to fill out the anonymous paper survey questionnaire at the meeting place. The data was saved to an Excel file. Stata version 14 (StataCorp., College Station, Texas) was used to perform the statistical analysis. A descriptive analysis was obtained followed by bivariate analysis to detect a statistical association between the patient's independent variables and their standpoint (Yes/No) on the acceptance of use of computer for communication with their doctor. A p-value of $<0.05$ was considered statistically significant. Chi-square test was used to compare the response of participants according to their characteristics. For data where the number of participants was less than seven, Fisher's exact test was performed.

\section{Results}

\section{Study participants}

There were 125 patients who completed the questionnaire. The mean age of participants was 38.4 (SD 15.1 [SD: standard deviation) years with ages ranging from 18 to 81 years. Approximately half of the participants were below the age of 35 years, $31.2 \%$ were $35-54$ years and $19.2 \%$ were 55 years and older. Out of the total number of participants, almost two-thirds (75.6\%) had attended college (Table 1 ). 


\section{Cureus}

Characteristics

n (\%)

Age (\%)

18-34 year

35-54 year

$>55$ year

24 (19.2)

Education level (\%)

Did not attend college

Attended College

93 (75.6)

Use computer (\%)

109 (87.2)

Use cell phone

121 (97.6)

Use computer to try to diagnose your self

Use computer to research medical condition

99 (79.8)

Hours of use of computer in a month for your health

$<2 \mathrm{hr}$

85 (69.7)

$>2$ hrs

Have used a patient portal before

TABLE 1: Characteristics of 125 participants who completed the survey questionnaire.

\section{Computer use pattern among study participants:}

The majority of participants who completed the survey used computer (87.2\%) and cellphones (97.6\%) in their everyday life. The percentage of participants who used computers to diagnose themselves was $61.6 \%$, and the percentage of those who used computers to research medical conditions was $79.8 \%$. Majority of participants $69.7 \%$ (85/125) used a computer for less than two hours a month. Almost half (55.2\%) of participants had used a patient portal in the past (Table 1).

\section{Opinions about using a computer for doctor-patient communication}

The idea that it is useful when the doctor uses a computer to communicate directly with the patient / synchronous communication was shared by $72 \%$ of participants. The majority $(81.1 \%)$ were in favor of receiving the health information from their doctor on their cellphone and computer. The majority were in favor to receive appointment reminders (88.7\%) on their cellphones and receiving wellness reminders on their computer (82.1\%). The majority were comfortable in sharing their health information with their doctors through a safe portal (75.8\%) and favored the idea that some of their health questions could be answered before their visit to the doctor (79.8\%). Participants also liked the idea to receive video education regarding their specific health concerns $(82.9 \%)$, and the use of health apps by the doctor to see and evaluate their health information (78.9\%) (Table 2). 


\title{
Cureus
}

Synchronous Doctor-Patient Communication

Would you find it useful if your doctor communicated with you directly through the computer?

Yes

Asynchronous Doctor-Patient Communication

Open to receive helpful health information from doctor on cellphone or computer

Yes

No

Open to receive appointment reminders on cellphone

Yes

Would you be comfortable sending your health information to a doctor through a safe portal

Yes

No

Would you like some of your health questions answered before your visit to the doctor

Yes

Open to receiving wellness reminders from your doctor through computer

Yes

Would it be helpful if your doctor send you video education regarding your specific health concerns

Do you think it would be helpful if your doctor could see and professionally evaluate the information on a health app that you are using?

\section{TABLE 2: Participants responses to survey questions}

\section{Influence of patient characteristics and use of computer on virtual patient-physician communication}

\author{
Synchronous Communication
}

The patients' characteristics and computer usage affected their opinions towards virtual patient-physician communication (as shown in Table 3). Younger patients and those with higher education level were in favor of the doctor communicating with them directly on the computer as compared to older patients and patients with lower education level, respectively $82 \%$ (in the age range of $18-34$ vs $37.5 \%$ aged 55 years and older; $p$ $<0.01$ ) and $46.7 \%$ (not college-educated vs $80.6 \%$ of those who attended college). Figure 1 shows the percentage of participants who were in favor of synchronous doctor-patient communication according to age. Hours of computer use also affected this opinion (67\% who used the computer for less than two hours a month vs $86.5 \%$ of those who used the computer more than hours a month; $p<0.05$ ) with those who used a computer for more than two hours per day preferred synchronous communication (Table 3). The use of a patient portal did not affect the opinion for the synchronous communication $(p>0.05)$. 


\section{Cureus}

\begin{tabular}{|c|c|c|c|}
\hline & Yes, n (\%) & No, n (\%) & p-value \\
\hline Age Groups (years) & & & $<0.001$ \\
\hline 18-34 & $51(82.3)$ & $11(17.7)$ & \\
\hline $35-54$ & $30(76.9)$ & $9(23.2)$ & \\
\hline$\geq 55$ & $9(37.5)$ & $15(62.5)$ & \\
\hline Education & & & $<0.001$ \\
\hline Did Not Attend College & $14(46.7)$ & $16(53.3)$ & \\
\hline Attended College & $75(80.6)$ & $18(19.4)$ & \\
\hline Hours of Computer Use & & & 0.03 \\
\hline$<2$ hours & $57(67.1)$ & $28(32.9)$ & \\
\hline$>2$ hours & $32(86.5)$ & $5(13.5)$ & \\
\hline Used Patient Portal Before & & & 0.08 \\
\hline Yes & $54(78.3)$ & $15(21.7)$ & \\
\hline No & 36 (64.3) & $20(35.7)$ & \\
\hline
\end{tabular}

TABLE 3: Participants' responses to survey questions for synchronous doctor-patient communication according to participant characteristics:

\section{In favor of synchronous telemedicine}

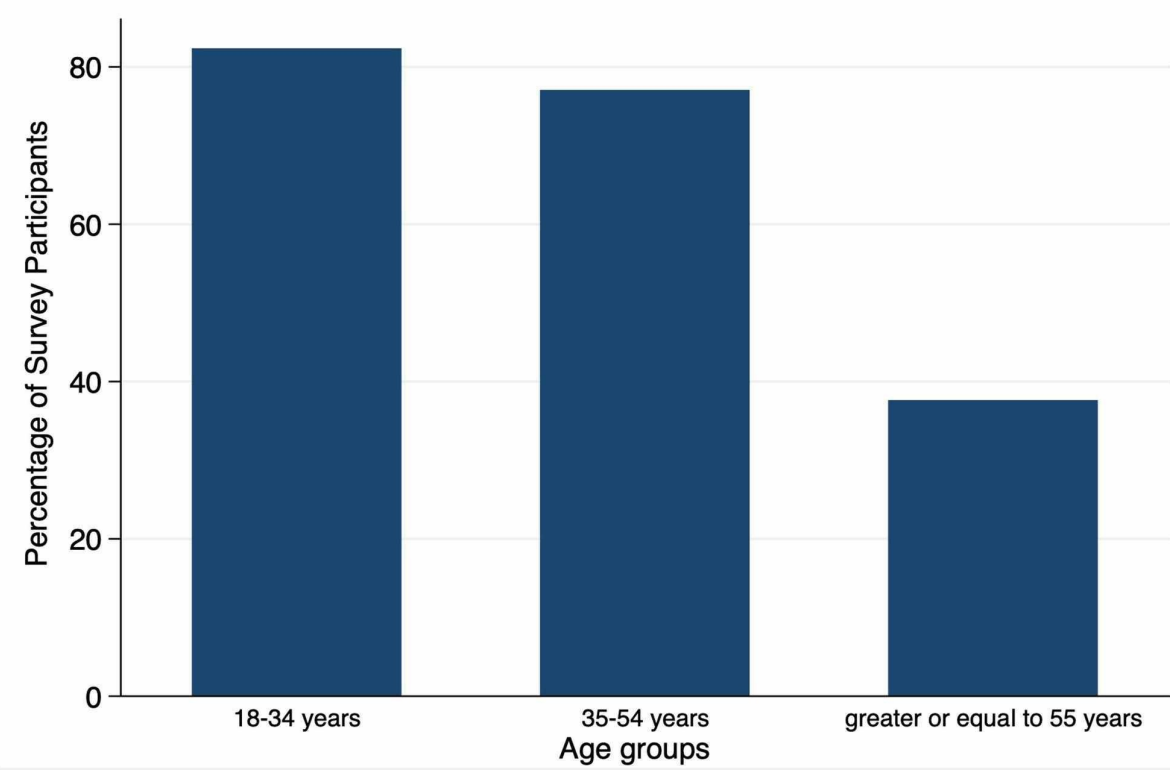

FIGURE 1: Percentage of survey participants in favor of synchronous communication according to age groups.

Asynchronous Communication

Figure 2 shows the use of patient portal according to age groups, and older age people were less likely to have used portal in the past (20.8\% use in age group 55 and older vs. $51.3 \%$ in those aged $35-53$ years vs $71 \%$ 


\section{Cureus}

in the 18-34 age group). Figure 3 shows the responses to asynchronous telemedicine according to prior use of patient portal in general public with mostly (>60\%) in favor of using it. Table 4 shows the responses of participants to questions on asynchronous communication according to age, education level, computer usage and prior use of patient portal.

\section{Responded 'yes' to "Ever used patient portal before"}

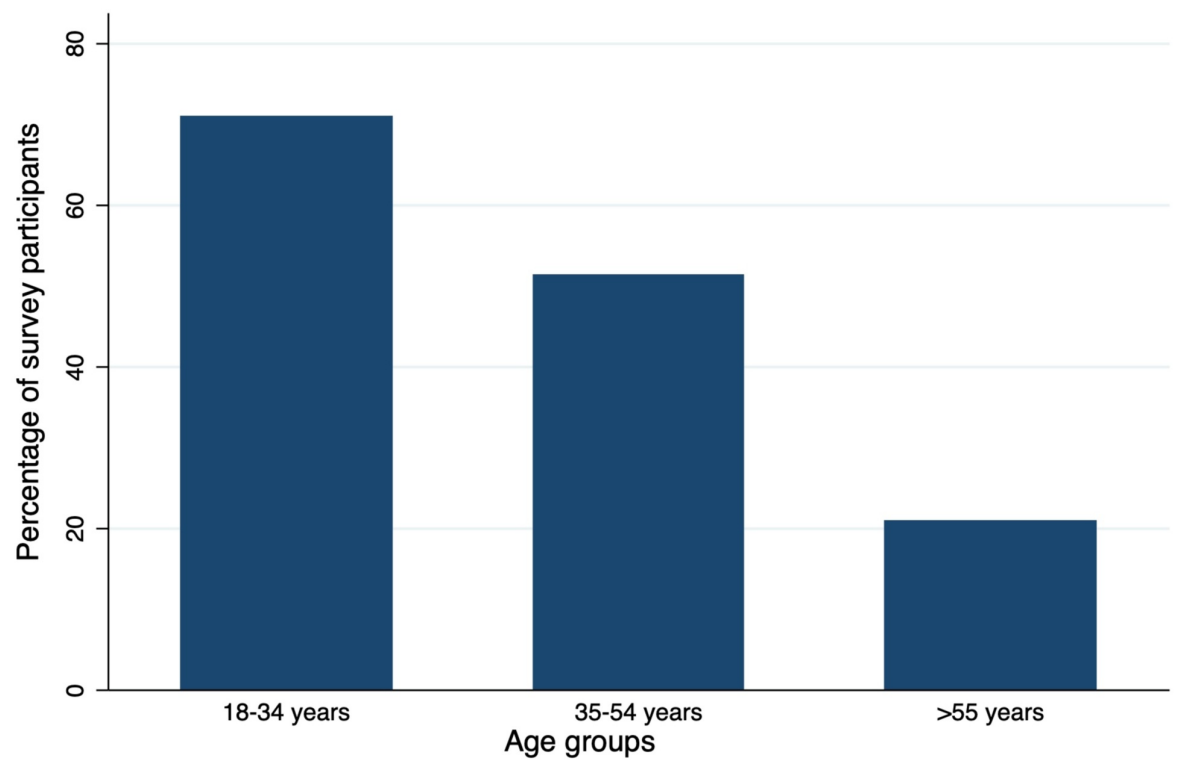

FIGURE 2: Percentage of survey participants who responded 'yes' to "have you ever used patient portal before" according to age groups.

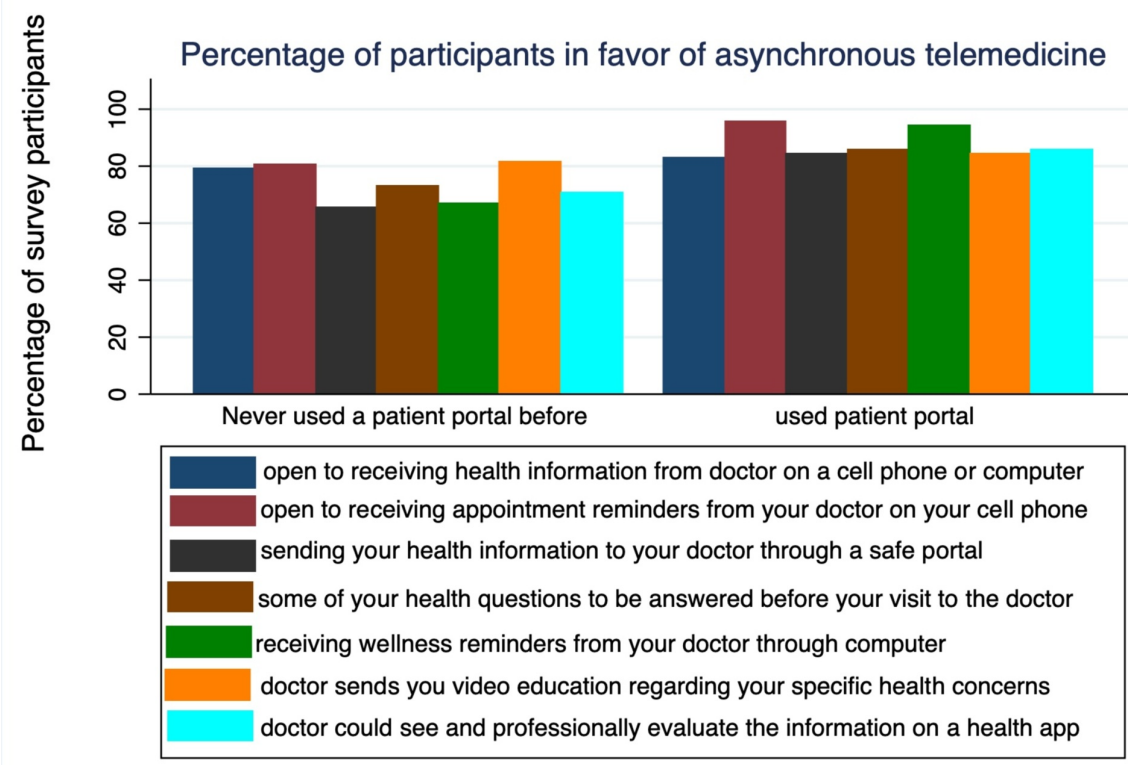

FIGURE 3: Percentage of survey participants who responded 'yes' to asynchronous telemedicine questions according to prior use of patient portal.

Q1: Would you be open to receiving health information from your doctor on a cellphone or computer?

Q2: Would you be open to receiving appointment reminders from your doctor on your cellphone? 


\section{Cureus}

Q3: Would you be comfortable sending your health information to your doctor through a safe portal?

Q4: Would you like some of your health questions be answered before your visit to the doctor?

Q5: Would you be open to receiving wellness reminders from your doctor through computer?

Q6: Do you think it would be helpful if your doctor send you video education regarding your specific health concerns?

Q7: Do you think it would be helpful if your doctor could see and professionally evaluate the information on a health app?

\begin{tabular}{|c|c|c|}
\hline Survey Questions & Yes, $n(\%)$ & No, $n(\%)$ \\
\hline \multicolumn{3}{|c|}{ Q:1 Would you be open to receiving helpful health information from your doctor on a cell phone or } \\
\hline \multicolumn{3}{|l|}{ Age groups (years) } \\
\hline 18-34 & $49(81.7)$ & $11(18.3)$ \\
\hline $35-54$ & $30(78.9)$ & $8(21.0)$ \\
\hline$\geq 55$ & 20 (83.3) & $4(16.7)$ \\
\hline \multicolumn{3}{|l|}{ Education } \\
\hline Not attended college & $22(75.9)$ & $7(24.1)$ \\
\hline Attended college & $76(83.5)$ & $15(16.5)$ \\
\hline \multicolumn{3}{|l|}{ Hours of computer use } \\
\hline$<2$ hours & $64(78.0)$ & $18(21.9)$ \\
\hline$>2$ hours & $32(86.5)$ & 5 (13.5) \\
\hline \multicolumn{3}{|c|}{ Used patient portal before } \\
\hline Used portal before & 57 (82.6) & 12 (17.4) \\
\hline Not used portal before & $42(79.2)$ & $11(20.7)$ \\
\hline
\end{tabular}

Q:2 Would you be open to receiving appointment reminders from your doctor on your cell phone?

Age groups (years)

$\begin{array}{lll}18-34 & 58(93.5) & 4(6.4) \\ 35-54 & 32(84.2) & 6(15.8) \\ \geq 55 & 20(83.3) & 4(16.7)\end{array}$

Education

Not attended college

$27(90.0)$

3 (10.0)

Attended college

82 (89.1)

$10(10.9)$

Hours of computer use

$<2$ hours

72 (84.7)

13 (15.3)

$>2$ hours

35 (97.2)

$1(2.8)$

Used patient portal before

Used portal before

65 (95.6)

3 (4.4)

Not used portal before

$45(80.4)$

11 (19.6)

Q:3 Would you be comfortable sending your health information to doctor through a safe portal?

Age groups (years) 


\section{Cureus}

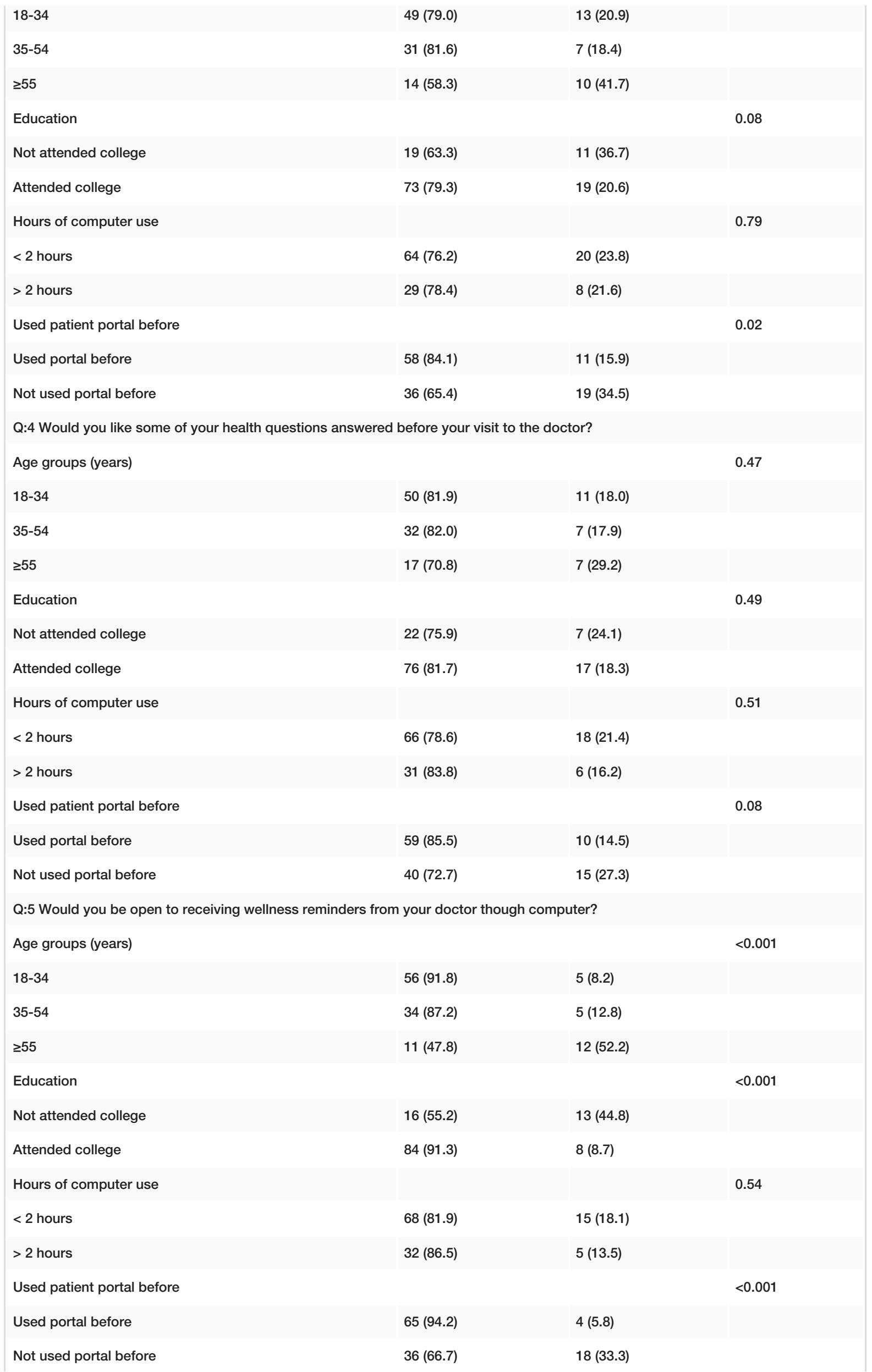




\section{Cureus}

Q:6 Do you think it would be helpful if the doctor sends you video education regarding your specific health concern?

Age groups (years)

18-34

35-54

$\geq 55$

Education

Not attended college

Attended college

Hours of computer use

$<2$ hours

$>2$ hours

Used patient portal before

Used portal before

Not used portal before
$50(81.9)$

$36(92.3)$

16 (69.6)

20 (71.4)

$80(86.0)$

64 (77.1)

35 (94.6)

58 (84.1)

44 (81.5)
0.07

$8(28.6)$

$13(13.9)$

$19(22.9)$

$2(5.4)$

11 (15.9)

11 (18.0)

$3(7.7)$

7 (30.4)

0.02

$10(18.5)$ using?

Age groups (years)

0.06

18-34

51 (83.6)

$10(16.4)$

$35-54$

$32(82.0)$

7 (17.9)

$\geq 55$

$14(60.9)$

9 (39.1)

Education

Not attended college

$18(64.3)$

$10(35.7)$

Attended college

77 (82.8)

16 (17.2)

Hours of computer use

$<2$ hours

65 (78.3)

$18(21.7)$

$>2$ hours

$31(83.8)$

6 (16.2)

Used patient portal before

Used portal before

$59(85.5)$

$10(14.5)$

Not used portal before

$38(70.4)$

$16(29.6)$

TABLE 4: Participants' responses to survey questionnaire for asynchronous doctor-patient communication according to participant characteristics.

* The total number of responses may not add to 125 in all questions because of missing data in some responses.

The participant age, education level, and use of computer and patient portal did not affect their opinion about receiving helpful health information from a doctor via computer, and the majority were in favor of it.

The idea of receiving appointment reminders on cell-phone was mostly favored by those who used patient portal with statistical significance, but it was not affected by participants age, usage of computer or education level. Only three participants out of total 125 did not use cell phones so we did not analyze the opinion about receiving appointment reminders on cell phone according to cellphone usage.

Those who had not used a patient portal in the past were less likely to be comfortable sending health information to their doctors via a safe portal as compared to those who had used it in the past (65.4\% vs 
84.1\%; $\mathrm{p}=0.02$ ). Age, education level and frequency of computer use did not affect their attitudes about sending information through a safe portal.

Patient characteristics, computer use and prior use of patient portal did not affect their opinion about health questions being answered prior to their visit.

The idea of receiving wellness reminders through a computer was favored by younger patients (91.8\% of 18 34 years of age vs $47.8 \%$ of 55 years of age; $p<0.01$ ), with higher education level $(91.3 \%$ who attended college vs $55.2 \%$ who did not attend college; $\mathrm{p}<0.01$ ), and those who had used patient portals in the past $(94 \%$ vs $66.7 \%$; $<0.01$ ), but infrequent use of computers did not affect the idea of receiving wellness reminders through a computer $(\mathrm{p}>0.05)$.

The idea of receiving video education for specific health concerns was particularly favored by those who used computer frequently $(94.6 \%$ who used computer $>2$ hours vs $77 \%$ who used computer $<2$ hours a month; $p$ $=0.02)$. Age, education level and portal use did not affect this opinion.

The opinion about use of health app by doctors to professionally evaluate health conditions did not differ by patient characteristics, frequency of computer use or use of patient portal, but it differed by education level.

Figure 2 shows the use of patient portal according to age groups, and older age people were less likely to have used portal in the past (20.8\% use in respondents aged 55 and older vs. $51.3 \%$ in the $35-53$ year age group vs $71 \%$ in those aged 18 -34 years ). Figure 3 shows the responses to asynchronous telemedicine according to prior use of patient portals in general public with mostly ( $>60 \%)$ in favor of using it.

\section{Discussion}

Computers have become an integral part in clinical practice without detrimental effects on patient satisfaction [10]. Good patient-physician communication is important for healing [11]. In this evolving era of medicine and communication, the purpose of our study was to inquire about the general public's perspectives about the use of telemedicine as well as suggest some methods for improvement. We found that majority of people were comfortable with their doctors communicating with them directly via computer, also known as synchronous telemedicine, a finding common to prior studies [12-14]. However, previous studies did not analyze these opinions according to patient characteristics. In our study, younger age, higher educational attainment and computer usage were identified as strong indicators for acceptance of synchronous telemedicine.

We evaluated general acceptance by participants to asynchronous telemedicine and provided some suggestions; using a patient portal, health concerns answered before a visit to doctor's clinic, receiving wellness reminders through the computer, receiving educational videos regarding specific health concerns, and use of health app by physicians for health evaluation. However, lack of prior use of a patient portal hampered the acceptance of this way of communication (Figure 3). Patient portals allow patients to remain engaged in their healthcare decisions and easily communicate with their physicians. Our study showed less use of patient portals by older adults (Figure 2). The main barriers identified are lack of technology, health literacy and distrust of online devices by older patients [15-16]. Therefore, step by step guidance for the use of patient portals in this age group is necessary.

We conducted the survey in general public and not just in physicians' clinics as there are many people who do not go to healthcare providers because of various reasons, such as lack of time and transportation. By conducting the survey in general public spaces, we were able to capture opinions of all types of people. Another strength of this study is that we categorized the people's opinions according to age, education level, computer usage, prior use of patient portals, and evaluated their views about both asynchronous and synchronous telemedicine. However, our study was conducted before the onset of COVID-19 pandemic during which telemedicine was the only way for most people to get their healthcare needs. It is likely to get more positive responses if the study is conducted during or after the pandemic and this opens door to future studies. Our survey methods had several limitations as it was not specified for a particular group, and people with certain health problems could have answered differently as compared to those without any health problems. This opens doors to future studies to evaluate the acceptance of telemedicine on a case by case basis. For example, tele-neurology is widely accepted for mental health evaluation, refills of medicines, neurorehabilitation, outpatient consultation, as well as pediatric neurology [17].

\section{Conclusions}

In conclusion, the use of computers for communicating with primary care physicians is generally accepted, however, clinicians should be mindful that older adults may not feel comfortable with synchronous telemedicine. People, especially older adults, should be encouraged to use computers and patient portals.

\section{Appendices}




\section{Cureus}

\section{Online Wellness Survey}

Q1: What is your age?

Q2: Do you use a computer at all?

o Yes

o No

Q2: Do you use a cellphone?

o Yes

o No

Q3: Would you be open to receiving helpful health information from your doctor on a cellphone or computer?

o Yes

o No

Q4: What is your education level at this point?

o Not attained high school diploma

o Graduate high school/ GED

o Some college

o Graduate college

o Graduate degree

Q5: Would you be open to receiving appointment reminders from your doctor on your cellphone?

o Yes

o No

Q6: Do you use a computer to try to diagnose yourself?

o Yes

o No

Q7: Do you use a computer to research a medical condition?

o Yes

o No

Q8: How many hours do you use a computer for your health information in a month?

o Less than 1 hour

o 1 to 2 hours

o 2 to 4 hours

o 4 to 8 hours

o More than 8 hours 
Q9: Have you used a patient portal before? (patient portals provide web access for your medical records from the hospital or doctor's office)

o Yes

o No

Q10: Would you find it useful if your doctor communicated with you directly on a computer?

o Yes

o No

Q11: Would you be comfortable sending your health information to your doctor through a safe portal?

o Yes

o No

Q12: Would you like some of your health questions to be answered before your visit to the doctor?

o Yes

o No

Q13: Would you be open to receiving wellness reminders from your doctor through the computer?

o Yes

o No

Q14: Do you think it would be helpful if your doctor sends you video education regarding your specific health concerns?

o Yes

o No

Q15: Do you think it would be helpful if your doctor could see and professionally evaluate the information on a health app that you are using?

o Yes

o No

\section{Additional Information}

\section{Disclosures}

Human subjects: Consent was obtained by all participants in this study. Animal subjects: All authors have confirmed that this study did not involve animal subjects or tissue. Conflicts of interest: In compliance with the ICMJE uniform disclosure form, all authors declare the following: Payment/services info: All authors have declared that no financial support was received from any organization for the submitted work. Financial relationships: All authors have declared that they have no financial relationships at present or within the previous three years with any organizations that might have an interest in the submitted work. Other relationships: All authors have declared that there are no other relationships or activities that could appear to have influenced the submitted work.

\section{References}

1. Arora NK: Interacting with cancer patients: the significance of physicians' communication behavior . Soc Sci Med. 2003, 57:791-806. 10.1016/s0277-9536(02)00449-5

2. Stewart MA: Effective physician-patient communication and health outcomes: a review. CMAJ. 1995, 152:1423-1433.

3. Roter DL: Physician/patient communication: transmission of information and patient effects . Md State Med J. 1983, 32:260-265.

4. Ha JF, Longnecker N: Doctor-patient communication: a review. Ochsner J. 2010, 10:38-43. 
5. Waller M, Stotler C: Telemedicine: a primer. Curr Allergy Asthma Rep. 2018, 18:54. 10.1007/s11882-0180808-4

6. Bartz CC: Nursing care in telemedicine and telehealth across the world [article in French] . Soins. 2016, 61:57-59. 10.1016/j.soin.2016.09.013

7. Allely EB: Synchronous and asynchronous telemedicine. J Med Syst. 1995, 19:207-212. 10.1007/BF02257174

8. Halterman JS, Fagnano M, Tajon RS, et al.: Effect of the school-based telemedicine enhanced asthma management (SB-TEAM) program on asthma morbidity: a randomized clinical trial. JAMA Pediatr. 2018, 172:e174938. 10.1001/jamapediatrics.2017.4938

9. Xu T, Pujara S, Sutton S, Rhee M: Telemedicine in the management of type 1 diabetes . Prev Chronic Dis. 2018, 15:E13. 10.5888/pcd15.170168

10. Crampton NH, Reis S, Shachak A: Computers in the clinical encounter: a scoping review and thematic analysis. J Am Med Inform Assoc. 2016, 23:654-665. 10.1093/jamia/ocv178

11. Street RL Jr, Makoul G, Arora NK, Epstein RM: How does communication heal? Pathways linking clinicianpatient communication to health outcomes. Patient Educ Couns. 2009, 74:295-301.

10.1016/j.pec.2008.11.015

12. Shaarani I, Taleb R, Antoun J: Effect of computer use on physician-patient communication using a validated instrument: Patient perspective. Int J Med Inform. 2017, 108:152-157. 10.1016/j.ijmedinf.2017.10.007

13. Heidt EL: Health information technology and physician-patient interactions: impact of computers on communication during outpatient primary care visits. J Am Med Inform Assoc. 2006, 13:236-237. 10.1197/jamia.M1999

14. Hsu J, Huang J, Fung V, Robertson N, Jimison H, Frankel R: Health information technology and physicianpatient interactions: impact of computers on communication during outpatient primary care visits. J Am Med Inform Assoc. 2005, 12:474-480. 10.1197/jamia.M1741

15. Wildenbos GA, Peute L, Jaspers M: Facilitators and barriers of electronic health record patient portal adoption by older adults: a literature study. Stud Health Technol Inform. 2017, 235:308-312.

16. Wong JI, Steitz BD, Rosenbloom ST: Characterizing the impact of health literacy, computer ability, patient demographics, and portal usage on patient satisfaction with a patient portal. JAMIA Open. 2019, 2:456-464. 10.1093/jamiaopen/ooz058

17. Patel UK, Malik P, DeMasi M, Lunagariya A, Jani VB: Multidisciplinary approach and outcomes of teleneurology: a review. Cureus. 2019, 11:e4410. 10.7759/cureus.4410 